\title{
ПЕРЕОСМЫСЛИВАЯ СОВРЕМЕННУЮ ИСТОРИЮ РОЖДАЕМОСТИ: СЕМЬЯ, ГОСУДАРСТВО И МИР-СИСТЕМА
}

\section{МихАИЛ КЛУПТ}

\begin{abstract}
Статья освещает «забытые» теорией движущче сильл современной истории рождаемости 6 развитых странах: фундаментальные изменения мир-системы после Второй мировой войны и на рубеже 1980-х и 1990-х годов; конкурирующие представления о «правильной» семье и семейной и демографической политике; иентр-периферийные отношения и их влияние на ресурсные возможности такой политики. Периоды, на протяжении которых ранжирование стран по величине суммарного коэффициента рождаемости оставалось устойчивым, нарушались, как свидетельствует статистический анализ, перерывами постепенности, во время которых это ранжирование существенно менялось. Дважды, после Второй мировой войнь и при распаде СССР и советского блока, такие перерывы совпадали с фундаментальными сдвигами в мировой системе. Кроме того, в странах Запада такой перерыв наблюдался на рубеже 1980-х и 1990-х годов при смене обратной зависимости между женской занятостью и рождаемостью напрямую, а затем в России, странах Центральной и Восточной Европь и бывщей Югославии в период «восстановительного» роста рождаемости в 2000-е годы. Современная динамика рождаемости в развитом мире направляется «гравитационными полями» четырех аттракторов. Три первых представляют собой институциональные ловушки, связанные либо с низким уровнем жизни, либо с противоречием между «новой» экономикой $и$ «старой» организачией семейных отномений, либо, в определенных пропорциях, тем и другим. Четвертым аттрактором является идеальное состояние, при котором щедрая семейная политика и участие мужчин в домашних заботах обеспечивают уровень рождаемости, необходимый для простого замещения поколений. Ближе всего к нему находятся в настоящее время Франция и скандинавские страны. Вопрос о том, смогут ли приблизиться к этому состоянию страны полупериферии развитого мира или из-за ресурсных ограничений оно останется привилегией, доступной только странам ядра, остается открытым.
\end{abstract}

Ключевые слова: рождаемость, демографическая политика, семейная политика, иентрпериферийные отношения, мир-система.

Различные, порой полярно противоположные интерпретации событий - характерная черта исторической науки. В отличие от этого интерпретации современной истории ${ }^{1}$ рождаемости не столь вариативны - все они, по выражению Д. Ван де Каa [Van de Kaа 1996], «привязаны к якорю» теории демографического перехода. Цель данной статьи представить иную трактовку изменений рождаемости, отчасти альтернативную этим теориям, а отчасти дополняющую их. МИХАИЛ АЛЕКСАНДРОВИЧ КЛУПт (klupt.m@unecon.ru), САНКТ-ПЕТЕРБУРГСКИЙ ГОСУДАРСТВЕННЫЙ
ЭКОНОМИЧЕСКИЙ УНИВЕРСИТЕТ, РОССИЯ.

СТАТЬЯ ПОСТУПИЛА В РЕДАКЦИЮ В ИЮЛЕ 2018 г.

${ }^{1}$ Под современной историей в данной статье понимается период от окончания Второй мировой войны до наших дней. 
Главным «мотором» и «интригой» современной истории рождаемости в нашей интерпретации выступит стремление государства примирить экономические и демографические функции семьи. В основе политики, направленной на достижение этой цели, лежали, как мы покажем ниже, конкурирующие между собой идеи о том, какими должны быть взаимоотношения семьи и государства. Сами же эти идеи и результаты их реализации в немалой степени определялись ходом политической истории и ее важнейшим элементом - центр-периферийными отношениями в мир-системе, а если смотреть на ход событий еще шире, - фрагментацией мира, в том числе развитого, на качественно различные и нередко находящиеся во взаимной конфронтации части.

\section{ИНЕРЦИОННОЕ РАЗВИТИЕ И ПЕРЕРЫВЫ ПОСТЕПЕННОСТИ: СТАТИСТИЧЕСКИЙ АНАЛИЗ}

Периодизация истории - один из канонических подходов к ее изучению. В нашем случае мы построим такую периодизацию, разделяя исторический поток на два типа периодов: стабильное развитие и перерывы постепенности. Вначале мы проведем такое разделение методами статистического (главным образом, корреляционного) анализа, а затем интерпретируем полученные результаты, поместив их в более широкий исторический контекст.

Наш статистический анализ охватывает две совокупности стран, относящихся к развитому миру. Первая состоит из 22 стран, которые на протяжении всего послевоенного периода либо входили в возглавляемый США военно-политический блок, либо, будучи формально нейтральными (как, например, Австрия и Швеция), неоспоримо принадлежали тем не менее к западному культурному ареалу ${ }^{2}$. Вторая (из 19 стран) включает Россию, европейские страны, ранее входившие в состав СССР или советский военно-политический блок, а также государства, ранее составлявшие Югославию ${ }^{3}$. В сумме обе совокупности включают 41 страну.

Первая совокупность стран включает только страны ядра и полупериферии развитого мира. Вторая до распада СССР и его геополитического блока представляла собой относительно обособленную часть мир-системы. В 1990-е годы и в начале XXI столетия некоторые из этих стран стали периферией, а некоторые - полупериферией развитого мира ${ }^{4}$. Временной горизонт анализа охватывал период с 1950 по 2016 г. В качестве

\footnotetext{
2 Австралия, Австрия, Бельгия, Великобритания, Германия, Греция, Дания, Испания, Италия, Канада, Нидерланды, Новая Зеландия, Норвегия, Португалия, США, Финляндия, Франция, Швеция, Швейцария, Южная Корея, Япония. Ввиду отсутствия в используемой нами базе данных необходимой информации по ГДР при проведении корреляционного анализа мы использовали временной ряд суммарных коэффициентов рождаемости с 1950 г. по 2016 г. по Германии в целом.

${ }^{3}$ Белоруссия, Болгария, Босния и Герцеговина, Венгрия, Литва, Латвия, Македония, Молдавия, Польша, Россия, Румыния, Сербия, Словакия, Словения, Украина, Черногория, Чехия, Хорватия, Эстония.

${ }^{4}$ Как видно из сказанного, мы используем некоторые понятия мир-системной теории И. Валлерстайна, но не стремимся к копированию его классификации государств. На наш взгляд, в развитом мире также можно выделить свое ядро, полупериферию и периферию. Среднедушевой доход в периферийных странах развитого мира намного уступает его ядру и полупериферии, но в то же время заметно превосходит значения этого показателя в наименее развитых (по классификации ООН) государствах планеты. Не менее важно и то, что для периферии развитого мира свойственны отрицательные темпы роста населения.
} 
исходных использовались данные о суммарных коэффициентах рождаемости для условного поколения (далее СКР), размещенные в электронном издании «Демоскоп Weekly» [Приложение Демоскоп Weekly 2018].

Перерывы постепенности в исторической динамике рождаемости проявляются в том, что места, занимаемые странами по уровню рождаемости в общей совокупности этих стран, подвергаются существенным изменениям. В силу этого анализ диагональной матрицы коэффициентов корреляции между СКР в рассматриваемых совокупностях стран позволяет выявить место перерывов постепенности на исторической оси ${ }^{5}$. Иными словами, полученные вышеописанным способом матрицы коэффициентов корреляции показывают, насколько сильно распределение стран на лидеров, «середняков» и аутсайдеров рождаемости, сложившееся к определенному году, детерминировано их предшествующей историей. Высокие значения коэффициентов корреляции свидетельствуют о том, что порядок, в котором выстроились страны, мало вариативен, а низкие - о его существенном изменении. Статистическая значимость коэффициентов корреляции (в случае, если она имеет место) позволяет отклонить нуль-гипотезу о том, что сходство в расположении стран в рассматриваемые годы носит случайный характер.

Результаты анализа свидетельствуют о том, что расположение стран по величине СКР обнаруживало, как правило, сильную зависимость от предшествовавшего развития (рисунок 1). С 1950 по 1980 г. в обеих совокупностях коэффициенты корреляции между СКР текущего года и СКР, наблюдавшимся десятилетием ранее, заметно превышали свои критические значения. Зависимость показателей рождаемости от предшествующего развития в этот период объясняется, на наш взгляд, сочетанием трех факторов: стабильностью формальных и неформальных институтов, тесно связанных с рождаемостью, стабильностью внешних по отношению к ним обстоятельств и отсутствием (за некоторыми исключениями) демографической политики, направленной на радикальное изменение тех и других. «Возмущения», обозначившиеся к концу данного периода (демографическая политика Венгрии, ГДР и Чехословакии, запрет на аборты в Румынии, падение испанской и португальской диктатур и последовавшее за ним снижение рождаемости) оказались, как показывает статистический анализ, недостаточно сильными, чтобы поколебать эту стабильность.

В то же время периоды инерционного развития, на протяжении которого расположение стран по величине суммарного коэффициента рождаемости менялось весьма медленно, несколько раз нарушались «перерывами постепенности», приводившими к существенному изменению в таком расположении. При этом совокупность из 22 стран в целом отличалась большей по сравнению с совокупностью из 19 стран стабильностью.

\footnotetext{
${ }^{5}$ Исходные данные для расчетов представляли собой матрицу значений СКР, строками которой являлись страны, а столбцами - годы. Рассчитывались коэффициенты корреляции между столбцами такой матрицы. Результатом расчетов является матрица, элементы которой представляют собой значения коэффициентов корреляции $r\left(C K P_{t}, C K P_{t-k}\right)$ между СКР в году $t$ и году $t-k$, отстоящем от года $t$ на $k$ лет назад. Коэффициенты корреляции в такой матрице представляют собой меры близости между годами, а не между странами.
} 


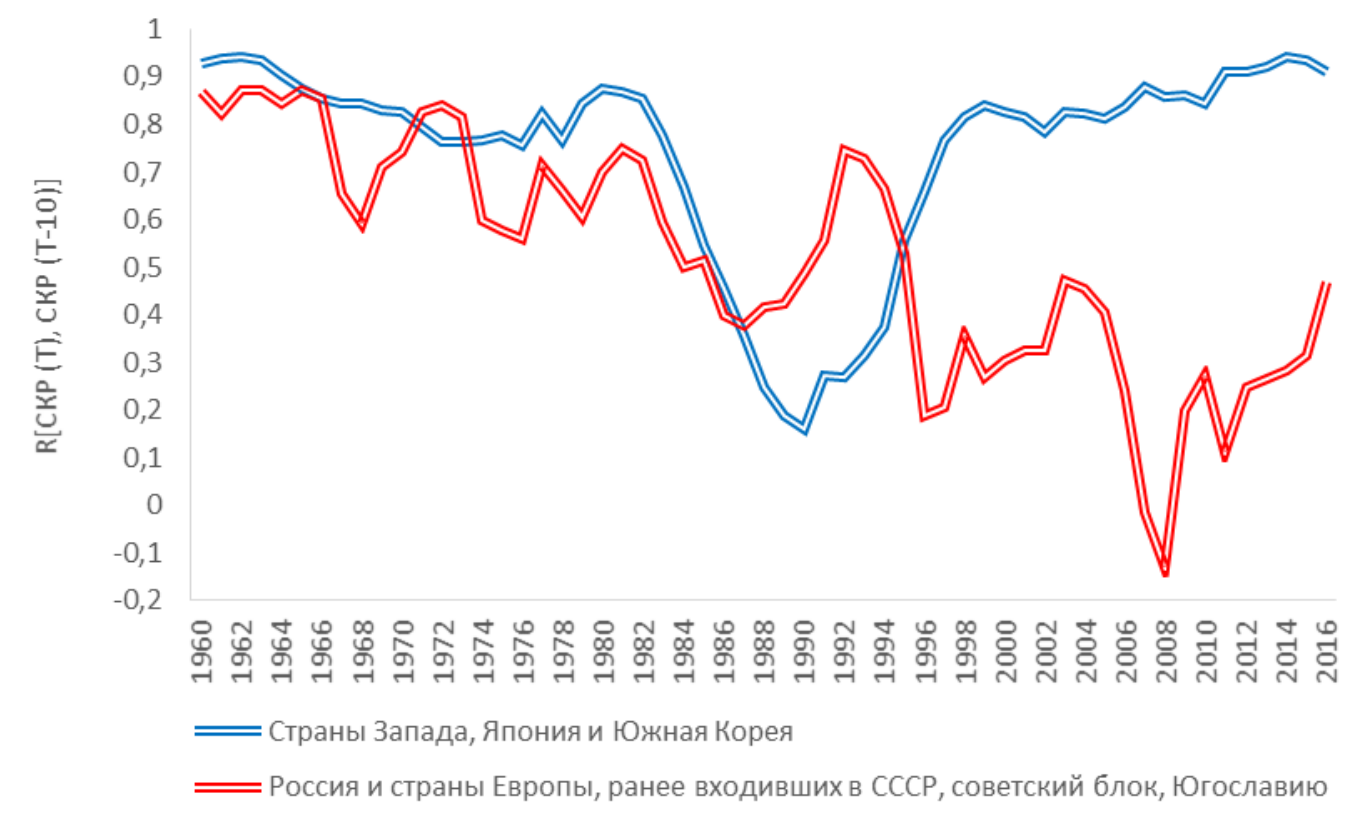

\section{Рисунок 1. Коэффициенты корреляции $r[C K P(t), C K P(t-10)]$ между величиной суммарных коэффициентов рождаемости в годы $t$ и $(t-10)$}

Источник: Расчеты автора на основе [Приложение Демоскоп Weekly 2018].

В совокупности из 22 стран период наиболее слабой зависимости от предшествующего развития приходится на 1987-1994 гг., когда коэффициенты корреляции между СКР, наблюдавшимися в текущем году и десятилетием ранее, опускались ниже своего критического значения на 5\%-ном уровне $(0,42)$. Во все остальные годы коэффициенты корреляции, рассчитанные подобным образом, были статистически значимы на 5\%-ном уровне.

Средняя величина СКР для рассматриваемых 22 стран в 2015 г. оставалась практически той же, что и в 2000 г. (соответственно 1,62 и 1,61). Почти не изменилось и их расположение по величине данного показателя: коэффициент корреляции между значениями СКР в 2000 и 2015 г. составил $0,83$.

В совокупности из 19 стран коэффициенты корреляции между СКР, наблюдавшимися в текущем году и десятилетием ранее, опускались ниже своего критического значения на 5\%-ом уровне $(0,46)$ трижды: в 1986-1989, 1996-2002 и 20062015 гг. Наиболее выраженными были при этом перерывы постепенности, связанные сначала с резким снижением СКР в ходе трансформационного шока, а затем в ходе их «восстановительного» роста, особенно быстрого в России 6 .

Для двух совокупностей вместе взятых (41 страна) различия между периодами, когда зависимость от предшествующего развития была достаточно сильной, и периодами, когда

${ }^{6}$ C 2000 по 2015 г. средняя величина СКР в этой совокупности стран (без учета данных по России) выросла с 1,36 до 1,51. В России значение СКР росло гораздо быстрее - с 1,20 до 1,78. При этом в вышеназванной совокупности из 19 стран зависимость от значений СКР, зафиксированных в 2000 г., начиная с 2007 г. уже не была статистически существенной. 
она нарушалась, хорошо видны на рисунке 2. Статистически значимая зависимость от величины СКР, наблюдавшейся в 1950 г., сохранялась не только в 1965 г., но и в 1980 г. (соответственно $r=0,61$ и $r=0,51$ ). В отличие от этого зависимость СКР от их значений, зафиксированных в 1980 и 1990 г., исчезала значительно быстрее и уже через 10-12 лет переставала быть статистически существенной.

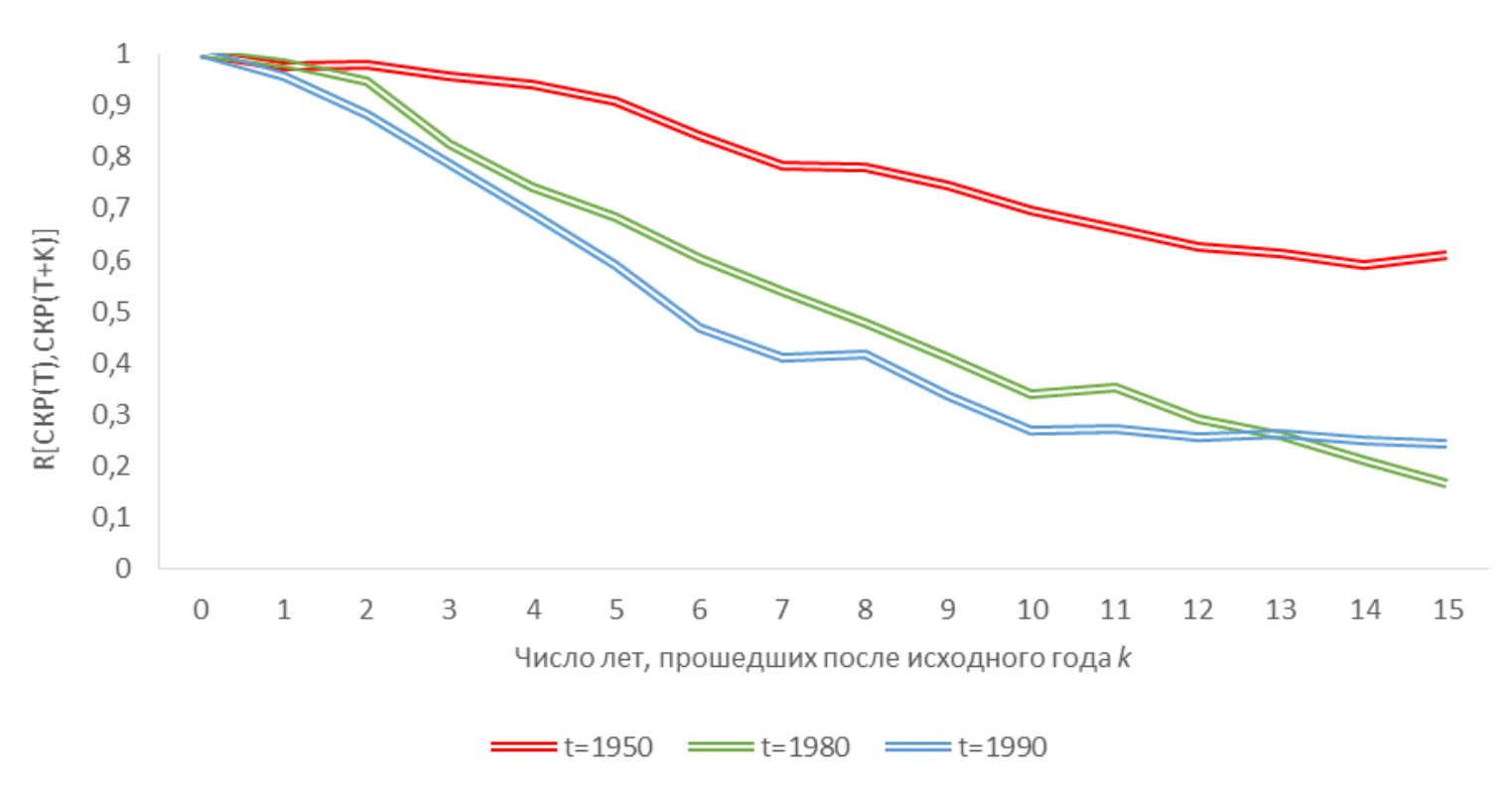

Рисунок 2. Коэффициенты корреляции $r[C K P(t), C K P(t+k)]$ между величиной суммарных коэффициентов рождаемости в году $t$ и годом, отстоящим от него на $k$ лет вперед, для 41 развитой страны

Источник: Расчеты автора на основе [Приложение Демоскоп Weekly 2018].

Зависимость от предшествующего развития наблюдается и в случае, когда в качестве показателя рождаемости используется среднее итоговое число рождений в когортах на одну женщину. Так, для 23 стран ОЭСР коэффициенты корреляции между средним числом рождений на 1 женщину в соответствующих когортах составили: для когорт 1950 и 1960 годов рождения 0,$816 ; 1960$ и 1970 годов рождения 0,$898 ; 1950$ и 1970 годов рождения 0,623. Все названные коэффициенты корреляции статистически значимы на уровне $\alpha=0,01^{7}$.

\section{ПОСЛЕВОЕННЫЙ БЭБИ-БУМ}

Рассмотрим теперь вышеприведенные данные в более широком контексте, включающем, наряду с политическими событиями и экономическими потрясениями, также и соревнование идей, лежавших в основе демографической и семейной политики государства. Данные идеи (их комплекс мы будем называть также семейной доктриной)

7 Расчеты автора на основе [Family Database 2018: data for Chart SF 2.1.В]. Заметим также, что преимущественное использование в нашем анализе СКР для условных поколений, а не когортных показателей, обусловлено тем, что последние значительно труднее привязать к определенным политическим событиям, поскольку каждая из когорт на протяжении своего жизненного пути проходила через многие из них. 
можно разделить на два крупных класса. Идеи, относящиеся к первому из них, основываются на предположении о том, что семья способна обеспечить приемлемый для общества уровень замещения поколений и без достаточно щедрого государственного поощрения рождаемости. Подобная доктрина связывает помощь семье прежде всего с борьбой с бедностью и не считает необходимым уделять особое внимание материальному стимулированию рождаемости. Второй комплекс идей, альтернативный первому, состоит в том, что «просто» семейной политики, направленной на борьбу с бедностью, недостаточно и демографические цели общества могут быть достигнуты только при активном стимулировании рождаемости государством. В период послевоенного бэби-бума обе идеи нашли свое выражение в политической практике.

Динамика рождаемости в этот период была в немалой степени обусловлена комплексом факторов, хорошо описываемых теорией демографического перехода. Другим фактором, на который обычно обращают меньше внимания, были итоги Второй мировой войны. Опосредующим звеном влияния этих итогов выступала демографическая политика, вследствие которой Франция, в период между двумя мировыми войнами уступавшая по уровню рождаемости Германии и Италии, в послевоенный период вышла вперед.

В западном мире идейный контекст бэби-бума включал две противоположные семейные доктрины. Одна из них господствовала во Франции, другая - в ФРГ и Италии, а крайних формах - во франкистской Испании. Франция продолжала довоенную демографической политику, характерными чертами которой был официально декларируемый пронатализм и щедрая помощь семьям с детьми. Генерал де Голль заявил в программной речи 2 марта 1945 г. о том, что «французское население не увеличивается, и Франция может превратиться в гаснущий великий светоч. Но и в этой области еще ничего не потеряно, если только мы хотим действовать. Нам нужно, чтобы в ближайшие десять лет на свет появилось 12 миллионов здоровых младенцев» [Де Голль 2004: 502-503].

Разгром фашизма во Второй мировой войне сделал проведение в ФРГ и Италии пронаталистской демографической политики невозможным, поскольку в нацистской идеологии поощрение рождаемости «истинных арийцев» было неразрывно связано с геноцидом других народов. В основе семейных доктрин Италии и ФРГ лежали теперь религиозно-консервативные принципы. Предполагалась, что «естественная семья», в которой отец является добытчиком и кормильцем, а мать - домохозяйкой и воспитательницей детей, вполне способна обеспечить достаточный уровень рождаемости и без щедрых пособий, подобных французским. Министр труда ФРГ полагал, например, что размеры французских пособий отбивают у отцов семейств желание работать [Niehus 1995: 311]. Если во Франции в 1957 г. появление третьего и последующих детей снижало (по сравнению с бездетной семейной парой) уровень жизни семьи лишь на $9 \%$, то в ФРГ такое снижение составляло при рождении третьего ребенка $36 \%$, четвертого - $39 \%$, пятого - $43 \%$, шестого - 46\% [Niehus 1995: 311].

Семейная доктрина испанского франкизма была крайним проявлением религиозноконсервативных взглядов на семью. Труд женщин за пределами семьи трактовался как социальное зло, отвлекающее женщину от ее естественного предназначения - рождения и воспитания детей. До перехода франкизма к более либеральной экономической политике 
трудовое законодательство узаконивало дискриминацию женщин в сфере занятости. Только в 1961 г. были отменены правовые акты, в соответствии с которыми женщины, вне зависимости от их желания, при вступлении в брак могли быть уволены с работы. Женщинам запрещалось занимать руководящие посты, замужним женщинам разрешалось работать по найму или заниматься коммерческой деятельностью только с согласия супруга [Nielfa Cristóbal 2003; Morago Garcia 2008: 247].

\section{ДЕМОГРАФИЧЕСКАЯ ПОЛИТИКА И РОЖДАЕМОСТЬ В 1970-Е И 1980-Е ГОДЫ}

СССР и страны советского блока. Свойственная периоду послевоенного бэби-бума стабильность расположения стран по уровню рождаемости начала нарушаться уже в 1970-е годы. Пришедшийся на них перерыв постепенности был во многом обусловлен двоякой фрагментацией мира в ту эпоху: с одной стороны, на Запад и противостоящий ему советский блок, с другой - на ядро, полупериферию и периферию самого Запада. Противостояние Запада и советского блока, охватывало в тот период едва ли не все сферы общественной жизни. Активизация демографической политики в СССР и странах советского блока в немалой степени была вызвана этим противостоянием.

Т. Фрейка писал тогда в журнале, отнюдь не склонном к пропаганде достижений советского блока, о том, что «молодые люди в Чехословакии живут, вероятно, в условиях демографической политики в области рождаемости, являющейся наиболее широкой, всеохватывающей и затратоемкой в мире» [Frejka 1980: 89]. Как когда-то во Франции, проведение такой политики было в немалой степени следствием внешнеполитических факторов. Население стран, образовывавших в то время «западный форпост» социализма, неизбежно сравнивало свой уровень жизни с уровнем жизни капиталистических соседей. Чтобы выжить в постоянном соревновании с географически и культурно близким Западом, правительства Венгрии, ГДР и Чехословакии должны были поддерживать достаточно высокие жизненные стандарты; демографическая политика была одним из методов решения этой задачи. Определенную роль играл, вероятно, и идеологический фактор: трактовка низкой рождаемости как свидетельства упадка всей социальной системы никогда полностью не исчезала с политико-демографической арены; она остается на ней и сейчас.

В результате мер демографической политики, принятых в 1970-1973 гг., СКР в Чехословакии вырос с 2,07 в 1970 г. до 2,46 в 1975 г., однако затем начал снижаться и к 1980 г. уже не превышал значений десятилетней давности. Сходный характер носила и динамика СКР в Венгрии и ГДР. Подобный характер динамики нередко трактуется как хрестоматийный пример эфемерности эффекта демографической политики. Однако, если рассматривать результаты демографической политики этих стран сквозь призму «соревнования двух систем», охватывавшего тогда все сферы общественной жизни, картина получается иной. Чехия, занимавшая в 1970 г. 39-е место по величине СКР среди 41 вышеперечисленной страны, к 1990 г. поднялась на 16-е место; Словакия с 16-го переместилась на 7-е, а Венгрия - с 36-го на 20-е. 
Демографическая политика СССР в 1980-е годы определялась в основном теми же мотивами, что и в вышеназванных странах советского блока. Кроме того, в России с ее огромной территорией тезис о необходимости роста населения всегда (за исключением, может быть, короткого периода 1990-х годов) воспринимался и «низами», и «верхами» как нечто естественное и не в последнюю очередь обусловленное необходимостью защиты территории от внешних вторжений. СКР в России увеличивался в этот период быстрее, чем в развитых странах. Если в 1980 г. Россия занимала по этому показателю 28-е место среди вышеназванной 41 страны, то в 1985 г. - 13-е. В условиях постоянных информационных войн и «соревнования двух систем» это обстоятельство, вне зависимости от того, было ли оно в действительности связано с демографической политикой государства или нет, воспринималось как несомненное достижение ${ }^{8}$.

Демографическая политика СССР и стран, входивших в советский блок, была, таким образом, вполне адекватной той общественной системе, для которой создавалась, и тем политико-идеологическим задачам, которые решала. Резкое снижение рождаемости в 1990е годы уже не имело отношения к этой политике и было вызвано трансформацией всей общественной, да и повседневной жизни.

Страны Запада. В период послевоенного бэби-бума влияние семейных доктрин на рождаемость в странах Западной и Южной Европы казалось несущественным. Однако, начиная с 1970-х годов это влияние стало проявляться все более явно. Различия между рангами 22 вышеназванных стран по величине СКР в 1975 и 1990 г. были разительными: статистический анализ свидетельствует о том, что оба ряда практически независимы друг от друга $(r=0,02)$. Значительный вклад в это различие внесло опережающее снижение рождаемости в странах Южной Европы (Греции, Испании, Италии и Португалии), которые (за исключением, может быть, Италии) находились в тот период на полупериферии развитого мира. СКР в этих странах снизился соответственно на 0,94, 1,44, 0,84 и 1,19 пункта при среднем снижении по рассматриваемой совокупности 22 стран на 0,40 пункта. Испания, занимавшая в 1975 г. 3-е место по величине СКР среди названных стран, к 1990 г. переместилась на предпоследнее 21-е место, Италия - с 7-го на последнее 22-е.

Современная история рождаемости в странах Южной Европы имеет как свои особенности, так и общие черты. В Испании и Португалии быстрое снижение рождаемости было тесно связано с переходом от автаркии к тесной интеграции в западный мир и его составную часть - Европейский Союз. В Испании процесс осторожного сближения с западным блоком наблюдался уже в 1960-е годы; можно предположить, что этот же процесс исподволь создавал предпосылки и для последующего снижения рождаемости. Однако триггером такого снижения стала смерть в 1975 г. испанского диктатора Ф. Франко и последовавшее вслед за этим принятие в 1978 г. новой Конституции, узаконившей равенство полов (рисунок 3).

8 Отметим обычно не замечаемую демографами и статистиками параллель между СКР для условного поколения и индикаторами финансовых рынков. И те, и другие, независимо от того, что в действительности отражают и правильно ли интерпретируются пользователями, влияют на их поведение, а следовательно, и на политическую и экономическую жизнь. 


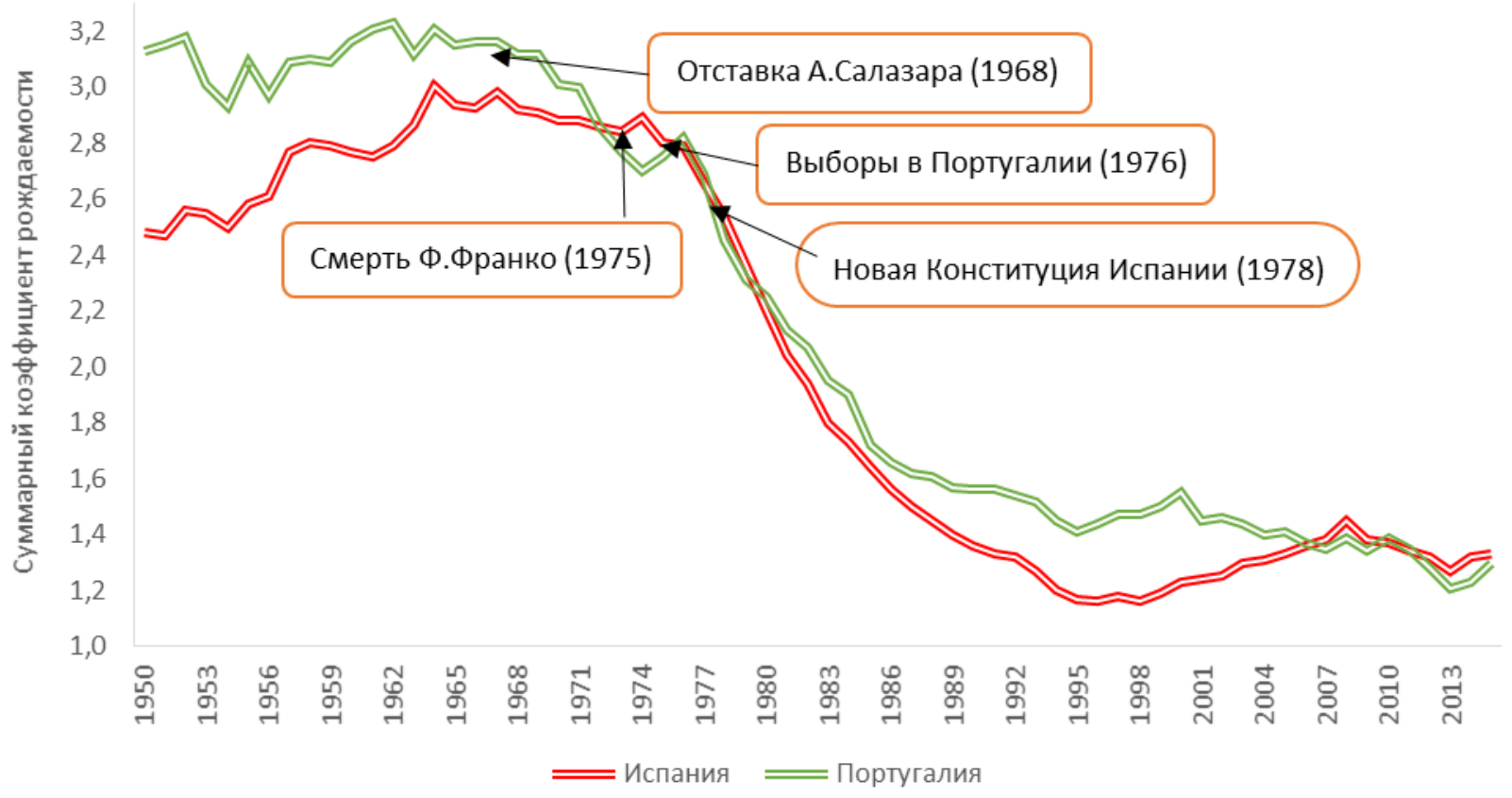

Рисунок 3. Суммарный коэффициент рождаемости в Испании и Португалии, 19502015

Следует также учитывать, что переход Испании к новой форме правления и интеграция этой страны в Европейский Союз происходили в условиях, когда «старой» семейной политики более не существовало, а новая существенно уступала большинству западноевропейских стран по масштабам оказываемой семьям помощи. Так, в Испании в 2001 г. расходы на семейную политику составляли 0,1\%, тогда как во Франции - 2\% [Meil Landwerlin 1995: 75]. В Португалии события развивались по сходному сценарию: и здесь быстрое снижение рождаемости началось вскоре после отставки А. Салазара (1968 г.), свержения диктатуры (1974 г.) и первых за полвека свободных парламентских выборов 1976 г. (рисунок 3). В целом же быстрое и глубокое снижение рождаемости в странах Пиренейского полуострова было, на наш взгляд, и «демографической ценой» отказа от обособленного развития и перехода на положение полупериферийной страны западного мира и в тоже время одним из многих свидетельств того, что модель семьи с отцомкормильцем и матерью-домохозяйкой не может более обеспечить простое замещение поколений.

В Италии, напротив, резкий спад рождаемости не был связан с радикальной сменой способа политического правления, происшедшей в Испании и Португалии. Скорее, можно говорить о некоторых знаковых событиях политической жизни, свидетельствовавших об умонастроениях в стране. К их числу безусловно относится референдум 1974 г., на котором большинство (59,3\%) итальянцев высказалось против отмены принятого незадолго до этого закона о либерализации порядка разводов, а также референдум 1981 г. - на нем 88,4\% избирателей проголосовало против отмены закона о либерализации абортов. 
Статистический анализ, проведенный Р. Риндфуссом и его соавторами [Rindfuss et al. 2003] для 22 стран ОЭСР ${ }^{9}$, показал, что обратная связь между уровнями занятости женщин и рождаемостью, наблюдавшаяся в 1970 г., к 1990 г. сменилась на прямую. В Швеции и Норвегии, для которых были характерны очень высокие уровни занятости женщин (в 1990 г. соответственно 81,0 и 67,2\% женщин в возрасте 15-64 года), СКР (2,13 и 1,93 в том же году) был в 1990 г. близок к уровню замещения поколений, тогда как в Испании и Италии низким уровням женской занятости (соответственно 31,8 и 36,2\%) сопутствовали очень низкие значения СКР $(1,36$ и 1,33) [LFS... 2018].

Тот факт, что уровень рождаемости в ФРГ был на протяжении всего послевоенного периода значительно ниже, чем во Франции, не привлекал к себе внимания до тех пор, пока рождаемость в обеих странах обеспечивала простое замещение родительского поколения поколением детей. Однако к середине 1970-х годов роль семейных доктрин стала очевидной: СКР Германии $(1,48)$ в 1975 г. уже существенно отличался от Франции $(1,93)$.

Существенный вклад в перерыв постепенности в рассматриваемый период внесли также Япония и, особенно, Южная Корея, переместившаяся с 1-го места по значению СКР среди названных 22 стран в 1975 г. на 14-е в 1990 г. Обе страны, озабоченные после окончания Второй мировой войны снижением, а не повышением рождаемости, попали в институциональную ловушку: противоречие между новыми экономическими реалиями и традиционными семейными институтами привело к тому, что женщины стали позднее вступать в брак и давать жизнь меньшему числу детей.

Свой вклад в перерыв постепенности, приходящийся на данный период, внесла и Швеция, где в 1986 г. была введена так называемая «премия за скорость», сделавшая для родителей экономически выгодным сокращение интервала между рождениями [Andersson, Hoem, Duvander 2005]. К 1990 г. СКР в Швеции достиг 2,13. Если в 1975 г. Швеция разделяла 16-е и 17-е места по значению СКР среди 22 названных стран, то в 1990 г. была уже второй.

Подводя итоги сказанному, отметим, что изменение, происшедшее в рассмотренном периоде в расположении стран западного блока по уровню рождаемости, было результатом нескольких причин. Одной из них было падение испанской и португальской диктатур и последовавший вслед за этим переход от изоляции к интеграции в капиталистическую мирсистему «на правах» ее полупериферии. Демографической ценой этого перехода, не сопровождавшегося принятием новой и достаточно щедрой семейной политики, оказалось быстрое и глубокое снижение рождаемости.

Другой причиной стало то, что на европейском континенте идеальная с религиозноконсервативной точки зрения доктрина «естественной» семьи с добытчиком-отцом и домохозяйкой матерью неожиданно оказалась несовместимой с сохранением приемлемого

\footnotetext{
${ }^{9}$ В нашем анализе в отличие от [Rindfuss et al. 2003] мы исключили из рассматриваемой совокупности 22 стран Люксембург и добавили к нему Республику Корею. В остальном рассматриваемые совокупности совпадают. URL: https://stats.oecd.org/Index.aspx?DataSetCode=LFS_SEXAGE_I_R\# (дата обращения: 05.05.2018).
} 
уровня рождаемости. Подобный ход событий стал ярким примером непреднамеренных последствий политики: в Европе аутсайдерами рождаемости к концу рассматриваемого периода оказались именно те страны, где, в силу различных исторических причин, идеал консервативный семьи воплощался государством в жизнь наиболее последовательно. В странах, модернизировавших, подобно Швеции, свою семейную политику так, чтобы она соответствовала новым реалиям и поддерживала совмещение родительской и профессиональной функций женщин, рождаемость оказалось более высокой.

История рождаемости в США отличается в этом отношении от европейской. Консервативно настроенные белые американцы, в семьях которых трое-четверо детей - не редкость, составляют значительную часть американского населения. В [Lesthaeghe, Neidert 2009] на основе статистического анализа показано, что голосование за республиканскую партию США и неприятие ценностей, лежащих в основе второго демографического перехода, тесно связаны. Победы республиканцев на президентских выборах и выборах в конгресс в 2016 г. являются косвенным свидетельством того, что численность этой группы населения США по-прежнему очень значительна.

\section{МИНУВШИЕ ЧЕТВЕРТЬ ВЕКА И ПЕРСПЕКТИВЫ}

Распад СССР и советского блока повлек за собой и новые, и весьма значительные изменения в расположении стран по уровню рождаемости. К 2000 г. это расположение существенно отличалось от 1990 г. - ранги стран, ранее входивших в СССР, советский блок или Югославию, резко понизились. Платой за интеграцию в мир-экономику, как и в случае Испании и Португалии, стало резкое снижение рождаемости. Опосредующими факторами, относительная значимость которых по сей день остается дискуссионной, стали резкое снижение уровня жизни, изменение жизненных планов молодежи, практическим выражением которых часто становилась ее эмиграция в страны ядра мир-системы, более позднее рождение детей, а также деградация демографической политики. Россия, занимавшая в 1990 г. 18-е место по величине СКР, к 2000 г. стала 39-й; Венгрия отступила с 20-го на 27-е место, Польша - с 10-го на 23-е место, Чехия - с 16-го на 40-е. В 2000 г. различия между средними значениями СКР для стран, проходивших социальноэкономическую трансформацию $(1,35)$, и остальными государствами рассматриваемой совокупности $(1,61)$ были статистически значимы по $t$-критерию на уровне $\alpha<0,001$.

Политическая и экономическая реструктуризация мира повлекла за собой и значительные изменения в характере зависимости между уровнем жизни и рождаемостью и в развитых странах. Если в 1950 г. в странах с развитой рыночной экономикой зависимость между среднедушевым ВВП(ППС) и СКР не наблюдалась $(r=0,07)$, то к 1990 г. обозначилась уже достаточно явно $(r=0,425 \text {, значим на уровне } \alpha=0,05)^{10}$. При этом оказалось, что высокий среднедушевой доход является лишь необходимым, однако недостаточным условием относительно высокой рождаемости (таблица 1).

10 Расчеты автора на основе [Приложение Демоскоп Weekly 2018; Maddison 2010] в 1990г. для 22 вышеназванных стран, в 1950 г. для тех же стран без Южной Кореи. 
Таблица 1. Распределение 22 стран с развитой рыночной экономикой по величине суммарного коэффициента рождаемости в 1990 г.

\begin{tabular}{|c|c|c|c|c|}
\hline \multirow[t]{2}{*}{ Страны со среднедушевым ВВП (ППС) } & \multicolumn{3}{|c|}{$\begin{array}{l}\text { Число стран с величиной суммарного } \\
\text { коэффициента рождаемости }\end{array}$} & \multirow[t]{2}{*}{ Всего стран } \\
\hline & менее 1,5 & $1,5-1,8$ & 1,8 и более & \\
\hline $\begin{array}{l}\text { Менее } 17 \text { тыс. долл. } \\
17 \text { тыс. долл. и более }\end{array}$ & $\begin{array}{l}6 \\
-\end{array}$ & $\begin{array}{l}3 \\
7\end{array}$ & $\begin{array}{l}2 \\
4\end{array}$ & 11 \\
\hline
\end{tabular}

Источники: Расчеты автора на основе [Приложение Демоскоп Weekly 2018; Maddison 2010].

После того, как ранее относительно обособленные от мировой экономики страны, входившие в СССР, советский военно-политический блок и Югославию, стали экономической периферией и полупериферией развитого мира, прямая зависимость между среднедушевым доходом и рождаемость на некоторое время заметно усилилась. В 2000 г. в совокупности 38 стран ${ }^{11}$ наблюдалась прямая $(r=0,59)$ и статистически значимая на уровне $\alpha<0,001$ связь между среднедушевым ВВП (ППС) и СКР (рисунок 4).

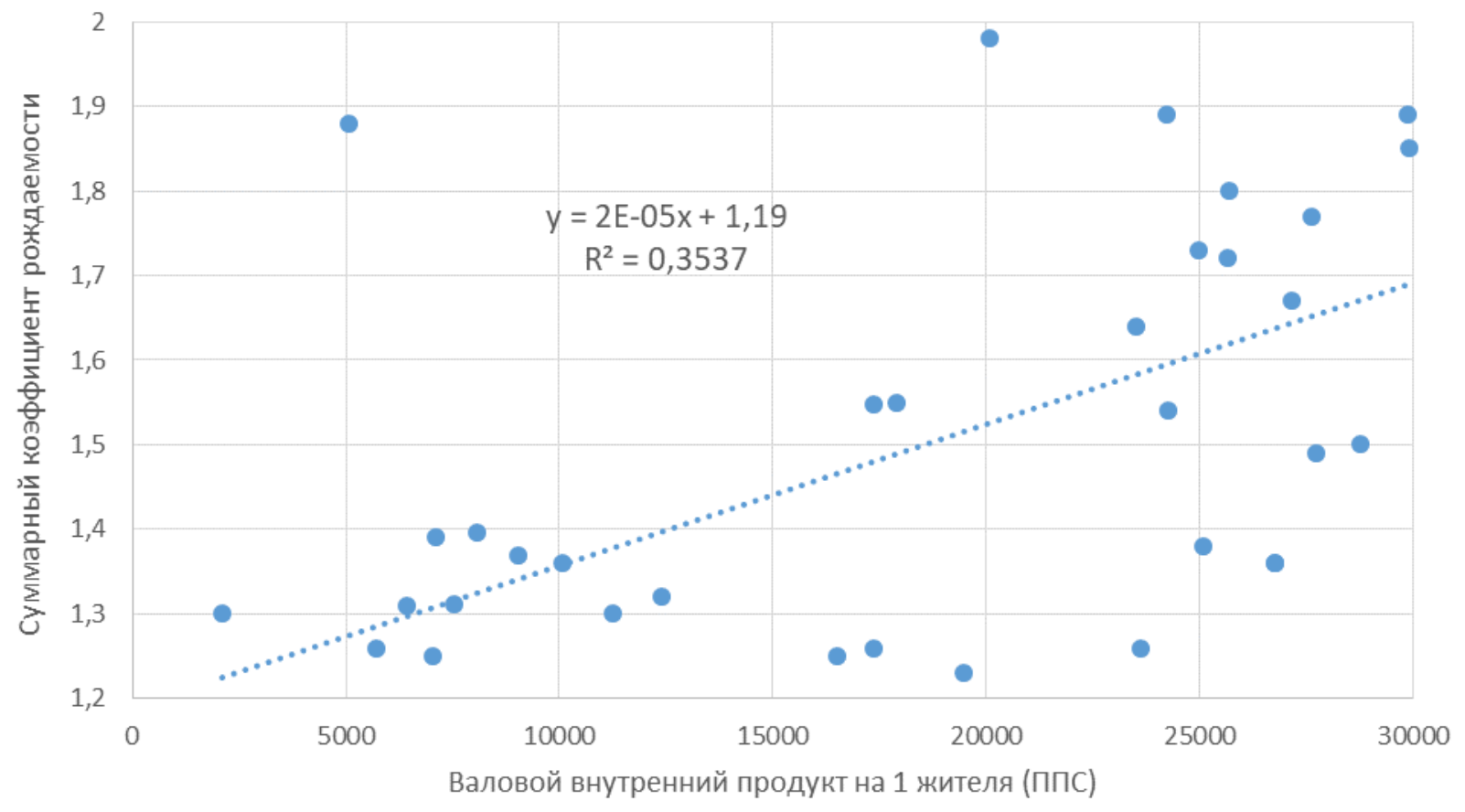

Рисунок 4. Валовой внутренний продукт и суммарный коэффициент рождаемости в 38 развитых странах, 2000 г.

Источники: [Приложение Демоскоп Weekly 2018; UNDP 2002: 149-152].

В 2015 г. связь между валовым национальным доходом (далее - ВНД) на 1 жителя и СКР для 41 рассматриваемой страны оставалось статистически существенной на 1\%-ном уровне $(r=0,41)$, хотя и не столь тесной, как полутора десятилетиями ранее. Как и в 2000 г., относительно высокий уровень рождаемости был доступен лишь странам, обеспечившим себе место в ядре мир-системы. Нахождение в таком ядре было, как и в 2000 г., хотя и

${ }^{11}$ Совокупность 41 стран, перечисленных выше, за вычетом Боснии и Герцеговины, Сербии и Черногории. 
необходимым, но недостаточным условием достижения уровня рождаемости, близкого к простому замещению поколений (таблица 2).

Таблица 2. Распределение стран периферии, полупериферии и ядра развитого мира по величине суммарного коэффициента рождаемости в 2000 и 2015 гг., \%

\begin{tabular}{|c|c|c|c|c|c|c|c|}
\hline \multirow[t]{2}{*}{ Год } & \multirow[t]{2}{*}{ Группа стран } & \multirow{2}{*}{$\begin{array}{c}\text { ВВП(ППС) } \\
\text { на } 1 \text { жителя*, } \\
\text { тыс. долл. }\end{array}$} & \multirow[t]{2}{*}{$\begin{array}{l}\text { Число } \\
\text { стран }\end{array}$} & \multicolumn{4}{|c|}{$\begin{array}{l}\text { Распределение стран } \\
\text { по величине СКР, \% }\end{array}$} \\
\hline & & & & менее 1,5 & $1,5-1,8$ & 1,8 и более & итого \\
\hline \multirow{3}{*}{2000} & Периферия & менее 10 & 11 & 90,9 & - & 9,1 & 100 \\
\hline & Полупериферия & $10-20$ & 9 & 77,8 & 22,2 & - & 100 \\
\hline & Ядро & 20 и более & 18 & 27,8 & 38,9 & 33,3 & 100 \\
\hline \multirow{3}{*}{2015} & Периферия & менее 20 & 9 & 33,3 & 66,7 & - & 100 \\
\hline & Полупериферия & $20-35$ & 16 & 56,3 & 37,5 & 6,3 & 100 \\
\hline & Ядро & 35 и более & 16 & 12,5 & 56,3 & 31,3 & 100 \\
\hline
\end{tabular}

Примечание: * - в 2015 г. валовой национальный доход (ППС) на 1 жителя.

Источники: Расчеты автора на основе [Приложение Демоскоn Weekly 2018; UNDP 2002: 149-152;

UNDP 2016: 198-201].

Следствием экономической и политической реструктуризации мира, происшедшей на рубеже 1980-х и 1990-х годов, стало формирование четырех аттракторов ${ }^{12}$. Первый из них представляет собой институциональную ловушку, «притягивающую» периферийные страны при их интеграции в капиталистическую мир-систему. Жизненные потребности молодежи периферийных стран в этом случае формируются на основе сравнения с более развитыми соседями, а невозможность удовлетворения этих потребностей влечет за собой снижение рождаемости. Дополнительным фактором такого снижения оказывается эмиграция значительной части населения периферийных стран в страны полупериферии и ядра мир-системы. Подобная ситуация наблюдается, например, в Молдавии и на Украине.

Второй аттрактор представляет собой институциональную ловушку другого типа. Низкий уровень жизни уже не является в этом случае фактором снижения рождаемости, поскольку его основной причиной оказывается противоречие между быстро меняющимся устройством жизни за пределами семьи и более инертными нормами семейных отношений. Эта ловушка притягивает к себе наиболее развитые страны мира (примерами являются ФРГ и Япония). Третий аттрактор влечет к себе страны полупериферии, сочетая в некоторой пропорции свойства первого и второго аттракторов.

Четвертый аттрактор также обладает притягательной силой, но в отличие от первых трех, является не ловушкой, а идеалом. В его основе лежит представление о том, что щедрая демографическая или семейная политика, помогающая женщинам сочетать родительские и материнские роли, и более равномерное, чем в консервативной семье, разделение домашних обязанностей между супругами, способна обеспечить уровень рождаемости, обеспечивающий простое замещение поколений. «Материальной основой» этого идеала, позволяющей не считать его чисто умозрительной утопией, является современная демографическая ситуация в странах Северной Европы и Франции, где рождаемость

12 Целесообразность заимствования этого понятия из синергетики понятия в нашем случае обусловлена тем, что оно определяет объект, притягивающий к себе другие объекты и являющийся их предельным состоянием. 
подошла к отметке простого замещения поколений ближе, чем в других развитых европейских странах.

Современному относительно высокому уровню рождаемости во Франции, например, в немалой степени способствовала своевременная трансформация семейной политики [Toulemon, Pailhé, Rossier 2008]. Эта политика, первоначально ориентированная на модель семьи с одним кормильцем, была впоследствии преобразована таким образом, чтобы облегчить женщинам сочетание материнской и профессиональной ролей. Развитие ситуации в странах Северной Европы, по мнению ряда авторов, дает надежды на то, что «вторая половина гендерной революции», выражающаяся в более широком вовлечении мужчин в домашние дела, приведет к росту рождаемости [Goldscheider, Bernhardt, Lappegârd 2015: 229].

Аттракторы, образующие систему с четырьмя центрами притяжения, определяли и, как можно предположить, будут в ближайшем будущем определять динамику рождаемости в развитом мире. В 1990-е годы первый из этих аттракторов «затянул» в свою ловушку страны, трансформировавшие свою социально-экономическую систему; к их числу относилась и Россия. По мере улучшения экономической ситуации, большинству названных стран удалось выйти из гравитационного поля этого аттрактора. Ближе всего к нему из стран, входивших ранее в СССР, находятся Украина и Молдавия.

Вырвавшись из ловушки первого аттрактора, страны, прошедшие в конце прошлого века через трансформацию социально- экономического и политического устройства, тем не менее не достигли четвертого. Демографической целью большинства правительств в странах, относящихся к периферии и полупериферии развитого мира, является сегодня достижение уровня рождаемости, свойственного таким странам ядра мир-системы, как Франция или США. Реализации этой цели препятствует, однако, отсутствие достаточных ресурсов, обусловленное их периферийными или полупериферийным положением. Более того, риск снова вернуться к прежним, крайне низким уровням рождаемости остается вполне реальным. Выход из сложившейся ситуации правительства данной группы стран все чаще видят в перераспределении имеющихся ресурсов в пользу демографической или семейной политики.

Демографическая политика современной России является образцом подобной стратегии, однако сегодня она уже не является чем-то беспрецедентным - eе, независимо от геополитической ориентации, берут на вооружение и другие страны. К числу самых недавних примеров относятся Венгрия и Польша. В 2016 г. новое правительство Польши объявило о начале реализации программы «Семья 500+», ранее обещанной избирателям. Эта программа предусматривает назначение пособия в размере 500 польских злотых (отсюда и «500+» в названии) семьям с двумя и более детьми [Kulczyk 2016]. Венгрия объявила о том, что, начиная с 2018 г., при рождении второго ребенка семьям будет прощаться половина долга по образовательным кредитам, а при рождении третьего - 
кредит целиком, будут введены новые налоговые льготы и оказана поддержка семьям, покупающим жилье в долг ${ }^{13}$.

Проблемы стран, попавших в поле притяжения второго и третьего аттракторов (типичными примерами являются соответственно ФРГ и Испания,) заключаются не только или не столько в нехватке ресурсов, сколько в инерции неформальных и формальных институтов, сформированных господствовавшими долгие годы семейными доктринами. К четвертому («идеальному») аттрактору более всего приблизились сегодня страны с высоким уровнем жизни. Достигнуть величины СКР, близкой к уровню простого замещения поколений, в XXI веке удалось, если речь идет о развитом мире, лишь странам с очень высоким среднедушевым доходом, к числу которых относятся Франция, Швеция, Ирландия, США и, с некоторыми оговорками, ряд других стран.

\section{ЗАКЛЮЧИТЕЛЬНЫЕ ЗАМЕЧАНИЯ}

Ряд методологов [Tilly, Goodin 2006] разделяют исследовательские стратегии, направленные на поиск общих законов и на поиск механизмов. Последние можно определить как цепочки, связывающие причины событий, сами события и их результаты. По выражению О.Ю. Малиновой, «механизм - это меньше, чем теория, но больше, чем описание, ибо может служить в качестве модели для объяснения других случаев» [Малинова 2013: 14]. Исследование механизмов тесно связано с диахроническими или, как их еще называют, «генетическими» объяснениями, цель которых - показать, каким образом последующие события произрастают из предыдущих.

Проведенный в данной работе анализ дает основание говорить о нескольких механизмах, связывающих политическую и демографическую историю. Один из них состоит в том, что пронаталистская демографическая политика в ряде случаев, хотя не всегда, возникает в качестве ответа на внешнюю угрозу. Цепочка причинно-следственных связей при этом порой оказывается очень длинной. Так, франко-прусская война 18701871 гг, оказав огромное влияние на французский политический класс, повлекла за собой возникновение французского пронатализма, который в свою очередь сыграл значительную роль в формировании демографической, а затем и современной семейной политики во Франции.

Другой механизм связывал интеграцию в капиталистическую мир-систему государств, которые ранее были от нее изолированы, со снижением в них рождаемости.

При всех очевидных различиях между странами, переходившими от более или менее выраженной автаркии к плотной интеграции в капиталистическую мир-систему, включение в нее во всех случаях оказывалось возможным только на положении полупериферии или периферии. Опосредующими звеньями между интеграцией и снижением рождаемости выступали в этом случае новые стандарты качества жизни и снижение барьерных функций границ. Противоречие между потребностями и возможностями разрешалось либо за счет

${ }^{13}$ URL: http://abouthungary.hu/blog/hungary-names-2018-the-year-of-the-family/ (дата обращения 04.08.2018). 
отказа от рождения вторых и последующих детей, либо путем эмиграции населения репродуктивного возраста в страны ядра, что опять-таки снижало рождаемость.

Хотя период трансформационного шока сегодня остался позади, характер влияния миграции на рождаемость по-прежнему оказывается тесно связанным с расположением стран на центр-периферийной шкале. Страны ядра мир-системы оказываются наиболее привлекательными для иммигрантов, тогда как периферийные страны становятся миграционными донорами и теряют репродуктивные контингенты. Полупериферийные страны занимают в этом отношении промежуточное и неустойчивое положение. Ярким примером является Испания, в которой экономический и иммиграционный бум в начале XXI века сменился после начала кризиса 2008-2009 гг. оттоком квалифицированной молодежи в страны европейского ядра. Низкая рождаемость, наблюдаемая на периферии и полупериферии развитого мира, оказывается, таким образом, следствием «встроенных» в мир-систему структурных ограничений, делающих относительно высокую рождаемость привилегией, доступной только самым богатым странам. Вопрос о том, возможно ли преодоление этих ограничений с помощью перераспределения ресурсов полупериферийных и периферийных стран развитого мира в пользу семейной и демографической политики, остается открытым.

\section{ЛИТЕРАТУРА}

Де Голль Ш. (2004). Военные мемуары. Т.3. Спасение 1944-1946. М.: АСТ, Астрель, Транзиткнига. $799 \mathrm{c}$.

Демоскоп Weekly. Приложение (2018). Коэффициент суммарной рождаемости. URL: http://www.demoscope.ru/weekly/app/app4007.php (дата обращения: 14.04.2018).

Малинова О.Ю. (2013). Конструирование смыслов: исследование символической политики в современной России. М.: РАН ИНИОН. 421 с.

Andersson G., J. A.-Z. Hoem, Duvander (2005). Social differentials in speed-premium effects in childbearing in Sweden // MPIDR working paper 2005-027. URL: www.demogr.mpg.de/papers/working/wp-2005-027.pdf (дата обращения: 05.05.2018).

Goldscheider F., E. Bernhardt, T. Lappegârd (2015). The gender revolution: a framework for understanding changing family and demographic behavior // Population and Development Review. 41 (2): 207-239.

Family Database (2018). OECD. URL: http://www.oecd.org/els/family/database.htm\#TOP (дата обращения: 30.04.2018).

Frejka T. (1980). Fertility trends and policies: Czechoslovakia in the 1970s // Population and Development Review: 6(1) 65-93.

Kulczyk M. (2016). Family rights and family policy in Poland. European Center for Law and Justice. URL: http://media.aclj.org/pdf/Marcin-KULCZYK-Family-rights-and-family-policyin-Poland.pdf (дата обращения: 28.04.2018).

Lesthaeghe R., L. Neidert (2009). Presidential elections and the spatial pattern of the American second demographic transition // Population and Development Review. 35(2): 391-400. 
LFS (2018). LFS by age and sex - indicators. OECD. URL:

https://stats.oecd.org/Index.aspx?DataSetCode=LFS_SEXAGE_I_R\# (дата обращения: 30.04.2018).

Maddison A. (2010). Historical statistics of the world economy. URL: www.ggdc.net/maddison/historical_statistics/horizontal-file_02-2010.xls (дата обращения: 28.04.2018).

Meil Landwerlin G. (1995). Presente y futuro de la política familiar en España // Reis. Revista española de investigaciones sociológicas. 1(70): 67-90.

Morago Garcia M. (2008). Notas sobre la situacion jurídica De la mujer en el franquismo // Feminismo/s. 12: 229-252.

Nielfa Cristóbal G., ed. (2003). Mujeres y hombres en la España franquista: sociedad, economía, política, cultura. Madrid. 303p.

Niehus M. (1995). French and German family policy 1945-60 // Contemporary European History. 4(3): 293-313.

Rindfuss R., K. Guzzo, S. Morgan (2003). The changing institutional context of low fertility // Population Research and Policy Review. 22 (5/6): 411-438.

Tilly Ch., R. Goodin (2006). It depends // The Oxford Handbook of Contextual political analysis / Ch.Tilly, R.Goodin, eds. Oxford: Oxford University Press: 3-34.

Toulemon L., A. Pailhé, C. Rossier (2008). France: high and stable fertility // Demographic Research. 19: 503-556. URL: http://www.demographic-research.org/Volumes/Vol19/16 (дата обращения: 05.05.2018).

UNDP (2002). Human Development Report 2002. Deepening democracy in a fragmented world. NY. 277 p.

UNDP (2016). Human Development Report 2016. Human Development for Everyone. NY. $271 \mathrm{p}$.

Van de Kaa D. (1996). Anchored narratives. The story and findings of half a century of research into the determinants of fertility // Population Studies. 50(3): 389-432. 


\title{
RETHINKING THE CONTEMPORARY HISTORY OF FERTILITY: FAMILY, STATE, AND THE WORLD SYSTEM
}

\section{MIKHAIL KLUPT}

\begin{abstract}
The paper highlights the drivers of contemporary fertility history in developed countries, "forgotten" by theory: fundamental changes in the world system after the Second World War and at the turn of the 1980s and the 1990s; competing ideas of the "right" family and family and demographic policy; centre-peripheral relations and their impact on the resource capabilities of such policy. Statistical analysis shows that the periods during which countries' positions by total fertility rates remained stable were disrupted by intervals in which significant changes in these positions occurred. Twice, due to the Second World War and the disintegration of the Soviet bloc, such intervals coincided with fundamental shifts in the world system. In addition, such intervals occurred in Western countries at the turn of 1980s and 1990s, when the negative association between women's participation in the labour force and fertility became positive, and then in the 2000 s in Russia, countries of Eastern and Central Europe and the former Yugoslavia during fertility "recovery". Contemporary fertility changes in the developed world are directed by "gravitational fields" of four attractors. Three of them are institutional traps created by low living standards, or contradictions between the "new" economy and "old" family relations, or, in some proportions, both. The forth attractor is an ideal condition in which generous family policy and men's participation in the home maintain fertility at the replacement level. Currently, France and Scandinavian countries come closest to this. The question of whether the developed semi-peripheral countries will be able to approach this condition, or, due to resource constraints, it will remain a privilege accessible only to the core countries, remains open.
\end{abstract}

Key words: fertility, demographic policy, family policy, centre-peripheral relations, world system.

MikHail KluPt (klupt.m@unecon.ru), St. Petersburg State University of Economics (UNECON), Russia.

DATE RECEIVED : JULY 2018.

\section{REFERENCES}

Andersson G., J. A.-Z. Hoem, Duvander (2005). Social differentials in speed-premium effects in childbearing in Sweden // MPIDR working paper 2005-027. URL:

www.demogr.mpg.de/papers/working/wp-2005-027.pdf (accessed: 05.05.2018).

De Gaulle Ch. (2004). Voennye memuary [War memoirs]. T.3. [Vol.3]. Spasenie 1944-1946 [Salvation 1944-1946]. Moscow: AST, Astrel', Tranzitkniga. 799 p.

Demoscope Weekly. Prilozenie. [Demoscope Weekly Supplementary materials] (2018).

Koeffitsient summarnoy rozhdaemosti [Total fertility rate].URL:

http://www.demoscope.ru/weekly/app/app4007.php (accessed: 14.04.2018).

Family Database (2018). OECD. URL: http://www.oecd.org/els/family/database.htm\#TOP (accessed: 30.04.2018).

Frejka T. (1980). Fertility trends and policies: Czechoslovakia in the 1970s // Population and Development Review: 6(1) 65-93.

Goldscheider F., E. Bernhardt, T. Lappegârd (2015). The gender revolution: a framework for understanding changing family and demographic behavior // Population and Development Review. 41 (2): 207-239. 
Kulczyk M. (2016). Family rights and family policy in Poland. European Center for Law and Justice. URL: http://media.aclj.org/pdf/Marcin-KULCZYK-Family-rights-and-family-policyin-Poland.pdf (accessed: 28.04.2018).

Lesthaeghe R., L. Neidert (2009). Presidential elections and the spatial pattern of the American second demographic transition // Population and Development Review. 35(2): 391-400.

LFS (2018). LFS by age and sex - indicators. OECD. URL: https://stats.oecd.org/Index.aspx?DataSetCode=LFS_SEXAGE_I_R\# (accessed: 30.04.2018).

Maddison A. (2010). Historical Statistics of the World Economy URL: www.ggdc.net/maddison/historical_statistics/horizontal-file_02-2010.xls (accessed: 28.04.2018).

Malinova O.Yu. (2013). Konstruirovanie smyslov: issledovanie simvolicheskoy politiki v sovremennoy Rossii [Constructing Meanings: Study of Symbolic Politics in Modern Russia] Moscow: RAN INION. 421 p.

Meil Landwerlin G. (1995). Presente y futuro de la política familiar en España // Reis. Revista española de investigaciones sociológicas. 1(70): 67-90.

Morago Garcia M. (2008). Notas sobre la situacion jurídica De la mujer en el franquismo // Feminismo/s. 12: 229-252.

Niehus M. (1995). French and German family policy 1945-60 // Contemporary European History. 4(3): 293-313.

Nielfa Cristóbal G., ed. (2003). Mujeres y hombres en la España franquista: sociedad, economía, política, cultura. Madrid. 303p.

Rindfuss R., K. Guzzo, S. Morgan (2003). The changing institutional context of low fertility // Population Research and Policy Review. 22 (5/6): 411-438.

Tilly Ch., R. Goodin (2006). It depends // The Oxford Handbook of Contextual political analysis / Ch.Tilly, R.Goodin, eds. Oxford: Oxford University Press: 3-34.

Toulemon L., A. Pailhé, C. Rossier (2008). France: High and stable fertility // Demographic Research. 19: 503-556. URL: http://www.demographic-research.org/Volumes/Vol19/16 (accessed: 05.05.2018).

UNDP (2002). Human Development Report 2002. Deepening democracy in a fragmented world. NY. 277 p.

UNDP (2016). Human Development Report 2016. Human Development for Everyone. NY. $271 \mathrm{p}$.

Van de Kaa D. (1996). Anchored narratives. The story and findings of half a century of research into the determinants of fertility // Population Studies. 50(3): 389-432. 